\title{
'Spatial Narratives' in Architecture: Designing a Dance Institute for the Nomadic Kalbelia community at Pushkar, Rajasthan, in India
}

\author{
Namrata Singh \& Maulik Hajarnis \\ Faculty of Architecture, Parul University, Waghodia, Vadodara, Gujarat, India. \\ E Mail ID: hajarnismaulik@gmail.com
}

\begin{abstract}
The paper begins with an overview of the Storytelling potential of Architecture. It tells how the experiential process of moving through spaces and decoding the messages embodied in Architecture has the potential to nourish the perceiver spiritually and emotionally, going beyond the physical traits of the structure and imbibed functions. To understand how a designer can imbibe a narrative while designing a project, the paper then describes the design process of an academic project - A Dance institute for the Kalbelia community at Pushkar, Rajasthan, in India. The description ends with the experiential journey of the perceiver to decode the spatial narratives encoded by the conceiver while conceiving the project; supplemented with the drawings of the design proposal and the inferences.
\end{abstract}

Keywords: Spatial narratives, Storytelling, Architecture, Safeguarding Intangible Cultural Heritage, Kalbelia

\section{Architecture and Storytelling}

Architecture is a journey of movement and an unfolding of a mystery which conditions your mind and calms your temper, through a sequential unfolding of spaces. It is an act of 'Story-telling'. (Pandya, Workshop on 'Space-making in Architecture', 2014)

Architecture is a celebration of life. It encodes messages and emotes feelings. It may communicate through spatial tools, whether they be the space sequences and their organization; elements of space-making and their scale and form; or the symbolism of surface articulation. It sets off an instantaneous dialogue between the user and the architectural product. (Pandya, Concepts of Space in Traditional Indian Architecture, 2013)

\section{Modes of Perception}

Spaces created and orchestrated by Architecture are experienced by moving through them. This is where Architecture must go beyond problem solving and command its role as a nourisher for the psyche, nurturer for the emotions and a conditioner for the mind; an effective storyteller.

However, this experiential journey of the perceiver visiting the campus is a sum-total of his perceptions through various modes such as sensorial, associational, notional and experiential. The sensorial perception is generic to each person visiting a place and perceiving its spaces. But associational clues are decoded differently by each perceiver depending upon his ethnicity. This is because persons belonging to a specific ethnic origin can instantly decode and co-relate certain (c) AesthetixMS 2018. This Open Access article is published under a Creative Commons Attribution Non-Commercial 4.0 International License (http://creativecommons.org/licenses/by-nc/4.o/), which permits non-commercial re-use, distribution, and reproduction in any medium, provided the original work is properly cited. For citation use the DOI. For commercial re-use, please contact editor@chitrolekha.com 
traits or symbols to a specific faith, religion, region, community, or culture; while others may not be able to do so. Likewise, notional perception is also subjective and depends upon the preconceived ideas or notions in the minds of the people visiting the campus or place. Experiential perception again, is relative to the emotional and mental condition of the perceiver at the time of visit.

\section{Learning to embed a Spatial narrative in Architecture}

For an Architect, it is imperative to learn how to communicate through an Architectural expression. There are a couple of key determinants of Architecture such as Climate, Context, Condition, Construction, Community and Culture. Any design expression must be derived predominantly from one or more of these determinants. The resultant Architectural Design Expression is a sum-total of the main design decisions taken by the designer, namely Siting and Concept, Form and Massing, Space organization, Choice of elements, Materials and construction and Finishes - rendering. All of these, together conjure an experience, a story, a narrative which is sequentially unfolded by the perceiver during his visit.

Keeping the above considerations in mind, a format was designed for our final year students of Architecture. Based on the same, couple of good projects were furnished by them. One of the projects, which had turned up well as a design derived from the context, community, climate and culture was the Dance institute for the Kalbelia community at Pushkar, Rajasthan, India. The latter has been described here along with an overview of the Spatial narrative offered by the campus to the visitor.

\section{The Design Project}

This project was an academic attempt to safeguard the cultural heritage of the traditional Kalbelia folk songs and dance. This design seeks to re-interpret the traditional dance-form of the Kalbelias, translate it into an Architectural expression, retain the identity of their Nomadic culture, conform with the local climate and condition; and yet be a humble addition to the socio-cultural milieu of Pushkar.

\section{Intent of the project}

The proposed project aimed not only to safeguard the intangible cultural heritage element of the Kalbelia folk songs and dances, but also reinforce the confidence of the Kalbelia community people by building their capacities, educating their children up to primary schooling and training them for their traditional art form. It also sought to provide a platform for tourists or other interested people to learn the traditional dance form and associated art and crafts. Eventually the project wished to contribute to the upliftment and well-being of the Kalbelia community.

\section{Recognition of 'Kalbelia folk songs and dances' as an Intangible Cultural Heritage}

The Article 2.1 of the Intangible Cultural Heritage Convention held by UNESCO in 2003 defines the term "intangible cultural heritage" means the practices, representations, expressions, knowledge, skills - as well as the instruments, objects, artefacts and cultural spaces associated therewith - that communities, groups and, in some cases, individuals recognize as part of their cultural heritage. (Alzahrani, 2013)

Intangible heritage takes many forms, including oral expressions and traditions; performing arts; social practices, rituals and festive events; knowledge and practices concerning nature and the universe; and traditional craftsmanship. (UNESCO, 2012) 
'Kalbelia folk songs and dances of Rajasthan' have been recognized as an Intangible Cultural Heritage by UNESCO in 2010.
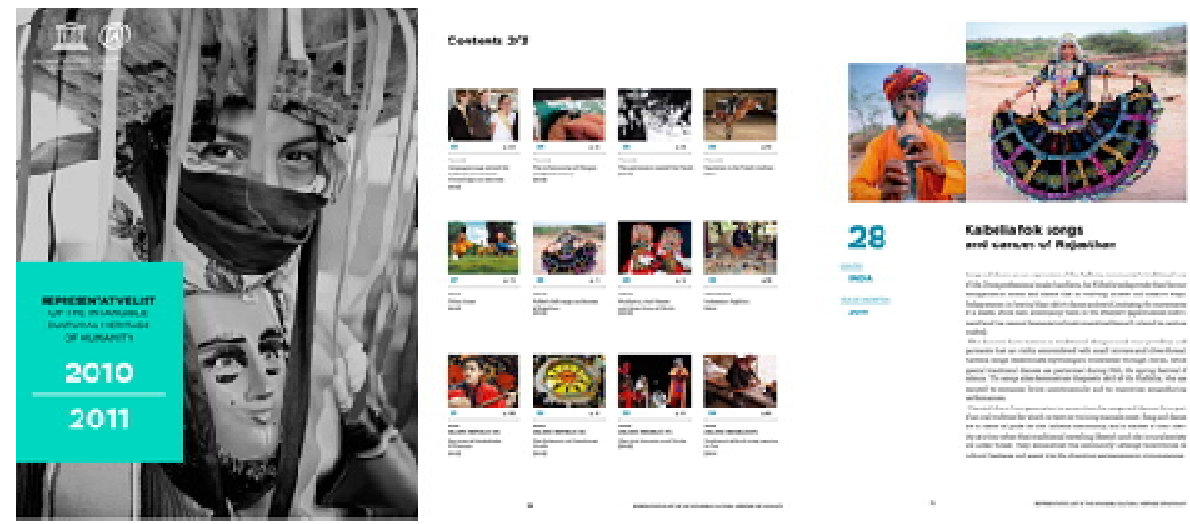

Figure 1: Glimpses of the Report on Representative List of the Intangible Cultural Heritage of Humanity (Source: https://ich.unesco.org/en/RL/kalbelia-folk-songs-and-dances-of-rajasthan-o034o)

\section{Safeguarding the Intangible Cultural Heritage of the Kalbelia folk songs and dances of Rajasthan}

First it is essential to understand the term 'Safeguarding', as defined by UNESCO in its Article 2.3:

'Safeguarding' means measures aimed at ensuring the viability of the intangible cultural heritage, including the identification, documentation, research, preservation, protection, promotion, enhancement, transmission, particularly through formal and non-formal education, as well as the revitalization of the various aspects of such heritage. (UNESCO, 2012)

On the same lines, the present study is an attempt to safeguard the Intangible Cultural Heritage of the Kalbelia folk songs and dances of Rajasthan by providing an institutional platform which would not only formalize the teaching - learning process of the dance form and its associations but also promote research and documentation, preservation, dissemination and revitalization of the traditionally inherited art.

In addition, the campus of the proposed institute would act as a destination which would house exhibitions, performances and festival celebrations thereby attracting tourists and other people to the place. This would also contribute in the revenue generation of the institute, which would be used for the betterment of the nomadic Kalbelia community children studying in the campus. 


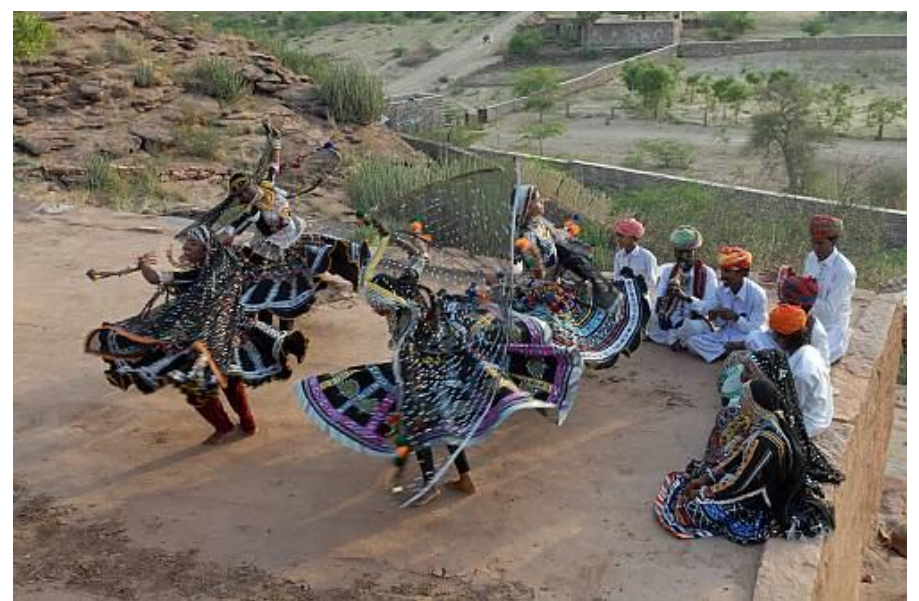

Figure 2: Kalbelia community members performing dance with music

(Source: Representative List of the Intangible Cultural Heritage of Humanity 2010 - 2011 by UNESCO)
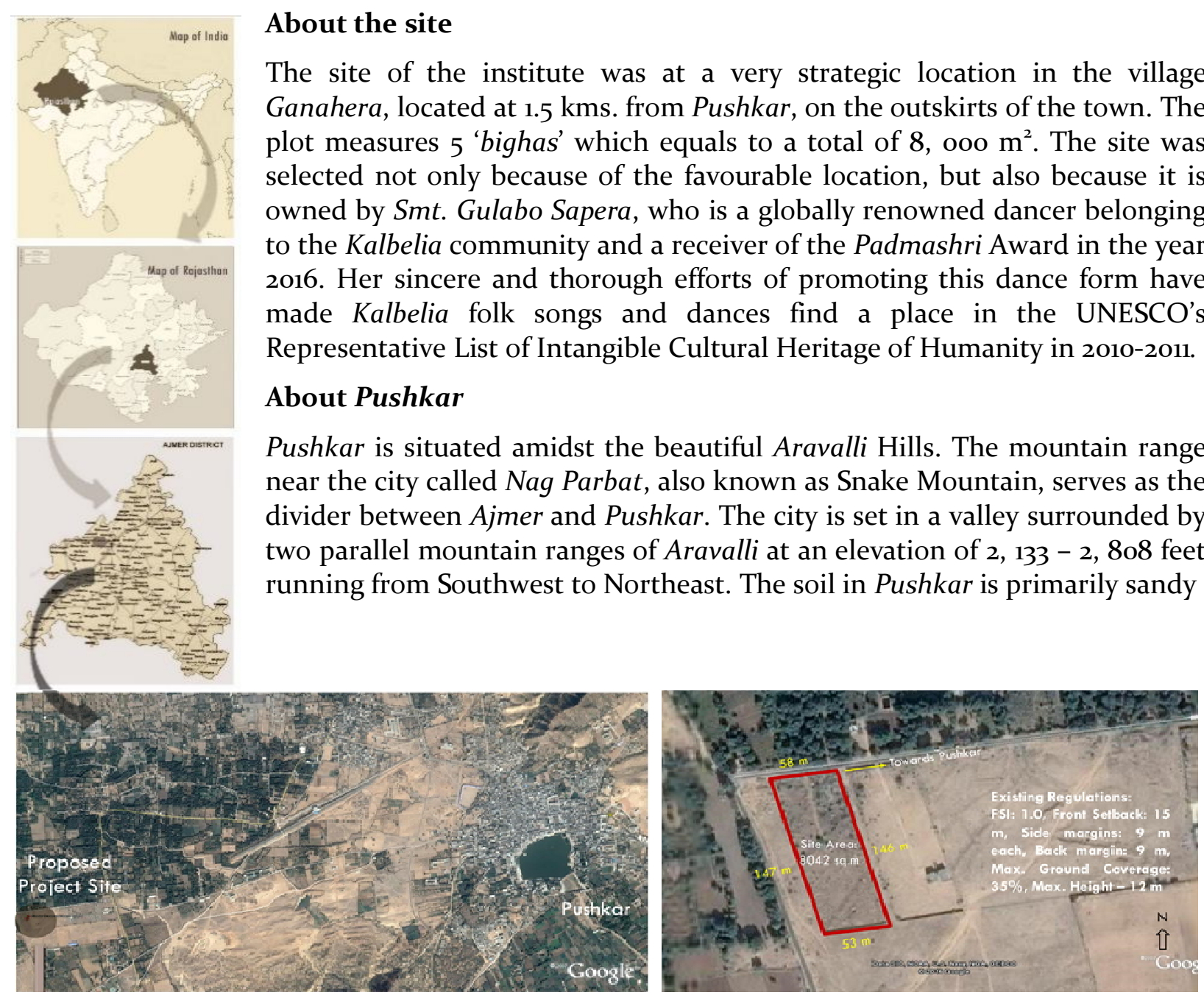

Figure 3: Maps - India-Rajasthan-Pushkar (top 3 on the left, Satellite imagery of the site with Pushkar town (bottom left) \& Satellite image of the site (bottom right) 
with little water retention capacity. The land use pattern that drains into the Pushkar Lake consists of 30 percent of the area under sand dunes, 30 percent under degraded and barren hills and 40 percent of the land in Pushkar is fit for agricultural use.

Pushkar is an ancient city and an important Hindu pilgrimage, located in the northwest of Ajmer. The place is popularly known as the town of fair and festivities. Flooded by national and international tourists and devotees, this town has become a leading tourist destination of Rajasthan.

The holy city of Pushkar is a sacred pilgrimage centre for Hindus. It has the only Brahma Temple in the world. It is considered as the king of all other pilgrimage sites in India. It is also famous for its 'camel fair'.

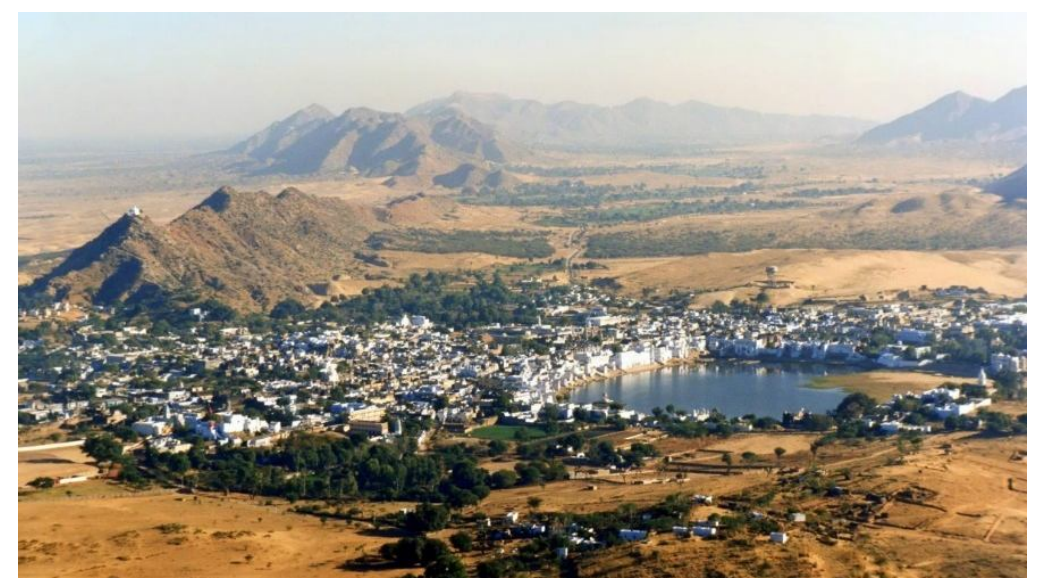

Figure 4: Aerial view of Pushkar town (Source: https://en.wikipedia.org/wiki/Pushkar)

\section{Applicable Regulations}

The building regulations applicable to the site were acquired from the Hindi document published in 2010 (applicable to cities with a population less than 1 lakh) prepared by Town Planning Department, Rajasthan, Jaipur as the Model Regulations. The same have been summarized as follows:

Maximum permissible FAR: 2.o, Front Setback: 15 m, Side margins: 9 m each, Back margin: $9 \mathrm{~m}$, Max. Ground Coverage: $35 \%$.

Height Restriction: In case where the plot / site is along a road with a width of less than 12 $\mathrm{m}$, the maximum height of the buildings shall be $12 \mathrm{~m}$. However, it could be allowed up to $15 \mathrm{~m}$, if the building/s is/are built on stilts.

\section{The Patron and the Client}

The project was to be developed by the Ministry of Culture on the land owned by Smt. Gulabo Sapera; who is a globally renowned dancer belonging to the Kalbelia community and a recipient of Padmashri Award in the year 2016.

\section{The Program}

\begin{tabular}{|c|l|l|l|}
\hline Sr. No. & Activity component & No. of users & Area $\left(\right.$ in $\left.\mathrm{m}^{2}\right)$ \\
\hline 1. & Administration \& Staff room & - & 90 \\
\hline 2. & Classrooms -7 & Per class 20 & 210 \\
\hline
\end{tabular}




\begin{tabular}{|l|l|l|l|}
\hline 3. & Dance studios -4 & Per studio 8 to 10 & 120 \\
\hline 4. & Music studios -2 & Per studio 8 to 10 & 90 \\
\hline 5. & Art and Craft workspace & 20 & 60 \\
\hline 6. & Exhibition and display area & - & 130 \\
\hline 7. & Computer Lab & 10 & 30 \\
\hline 8. & A.V Room & 20 & 30 \\
\hline 9. & Amphitheatre & 250 & 380 \\
\hline 10. & Canteen & 100 to 150 & 100 \\
\hline 11. & Dance Pavilions -2 & Per pavilion 8 & 520 \\
\hline 12. & Accommodation & 50 & 360 \\
\hline 13. & Library & 20 to 30 & 30 \\
\hline
\end{tabular}

\section{The Design Challenge}

The main design challenge in this project was to derive a design resolution that would reflect the identity of the nomadic Kalbelia community, respond to the local climate, relates to the contextual features, scale, proportions, elements, material, etc. and recall the essence of the Kalbelia dance-form; without compromising with the applicable regulations and the program of the project.

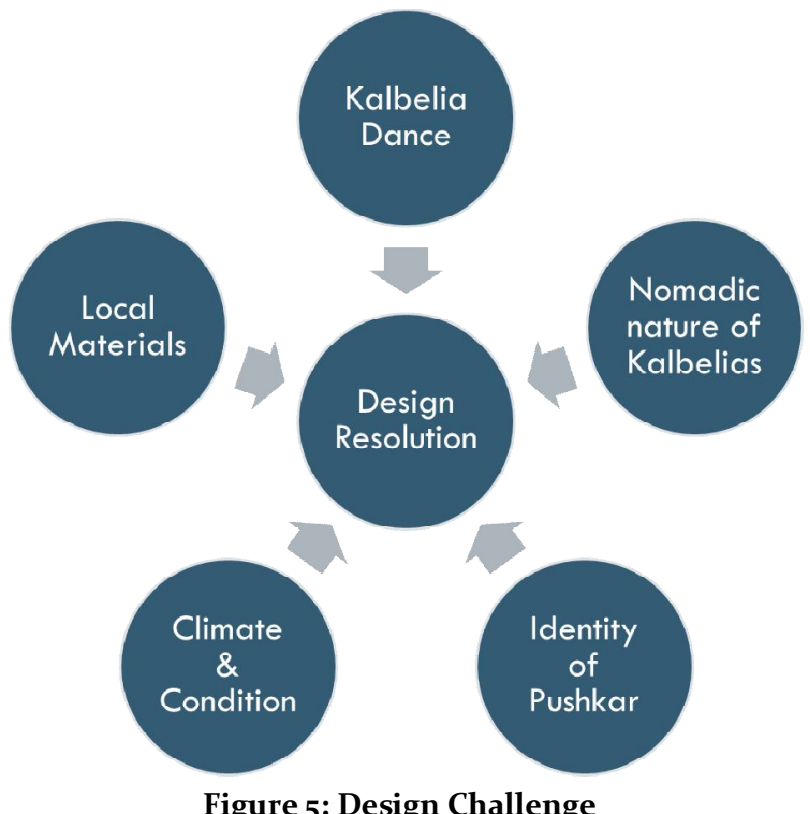

Figure 5: Design Challenge

\section{Design Guidelines}

Based on the study carried out and the design challenge formulated; the following design guidelines were framed for deriving a design for the undertaken project:

- Due to the regional abundance of various types of sandstone, the same material was to be used throughout the project.

- To reflect the nomadic identity of the Kalbelia community and to enhance visibility of the campus from a long distance, tensile tents were to be used throughout the campus, wherever suitable aesthetically. 
- Water might be utilized as an element for inducing evaporative cooling in spaces such as internal courtyards.

- Projections in the walls would be adopted to avoid heat gain due to direct sunlight falling on the entire surface.

- The walls would have to be thicker or be cavity-walls, to minimize heat gain during daytime.

- Use of building materials which are unsuitable in the Hot - arid climate of Pushkar, would have to be avoided.

- Perforated screens (Jaalis) would be used wherever needed, as sun breakers, as dust filters and for inducing wind pressure inside.

- To relate with the scale of the built context of Pushkar, all the built blocks in the design would be two storeyed $(\mathrm{G}+1)$ from the ground; despite having a provision of going higher as per the applicable regulations.

\section{Hierarchy of spaces}

All the activities of the program would be categorized into Public, Semi-public and Private areas of the campus. Following is the diagram showing the classification of various activities and functions of the project:

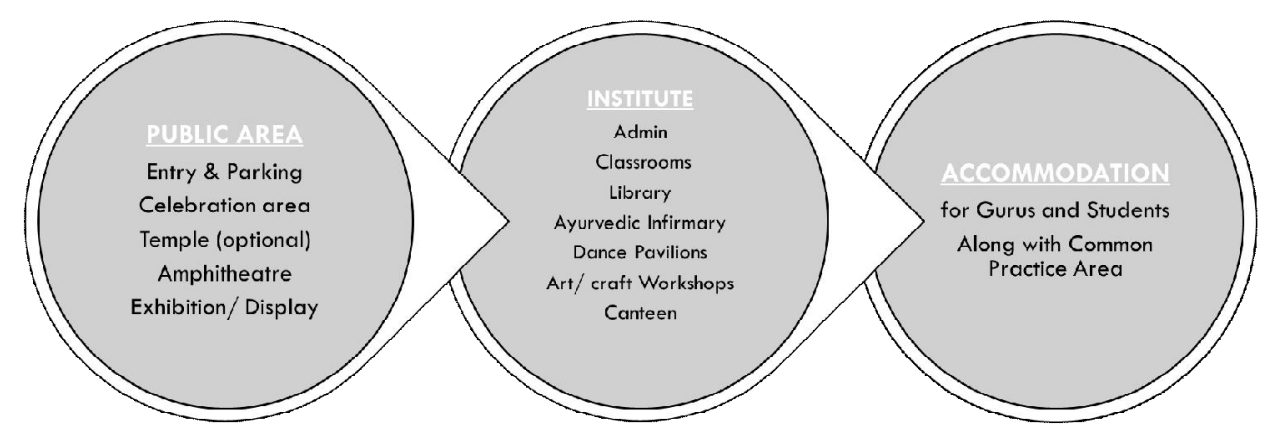

Figure 6: Clubbing of activities

\section{The Proposal:}

\section{Design Decisions}

Before directly rushing with glimpses of the design, it is imperative to sequentially understand the process of arriving at different design decisions, as per various principles of space-perception, through specific perspectives on Architecture and according to the contextual imprints.

All the design decisions taken for the project have been categorically justified below:

1. Siting and Location:

The selection of site was not an option because the design was to be suggested for the project already proposed at the land owned by Smt. Gulabo on the outskirts of Pushkar, Rajasthan.

2. Form and massing:

The design is a composition of several forms composed together, grouped together and balanced with a generous amount of landscape and open spaces. 


\section{Space organization:}

The space organization in this design was inspired from the sways of the Kalbelia dance moves. The site layout has a balance of landscape and built masses which together form a vista that besides attracting the visitor, clearly demarcate spaces and functional zones; and form a pattern of movement path for the visitor.

4. Choice of elements:

The notions of space are made physically manifest in architecture through the different elements that constitute the basic identifiable parts of the man-made built environment. Such elements possess attributes inherent to their morphological construct which endow them with particular spatial potential for their use and design in architectural compositions. (Pandya, Elements of Spacemaking, 2014)

Keeping the above in mind, a conscious and sensitive selection of elements was done for enhancing the spaces created through the design. Following is an account of all the elements adopted in the design, supplemented with their envisioned role in the composition:

a) Gateway: The entrance gateway in the design is a freestanding structure, more like a sculpture demarcating a notional entry to the campus. The form is a parabolic curve which is inspired by the smooth moves of the Kalbelia dance form.

b) Projected window: The projected window that is used on the first-floor enclosures of the built blocks, is an inspiration from the vernacular 'Jharukha' of Rajasthan. It overlooks the landscape and the street formed because of the composition. It also gives a scope of visual connection with the studios in the opposite building block. The perforated 'Jaalis' applied in these windows not only act as sun breakers but also induce ventilation to the interiors and filter the dust particles.

c) Water - bodies with lotus flowers: This element is induced in the landscape to not only greet the visitor but is an associational clue to the meaning of 'Pushkar' i.e. lotus.

d) Walls: The walls applied in the all the building blocks of the campus are thicker in section, to keep the heat out, act as insulators and meant to enclose the volume. In this case, the walls would together act as form givers. As for the compound wall, the element would demarcate the territory of the campus.

e) Tents: Tents (tensile structures) have been generously applied onto almost every built block in the campus. This is done with an intention to imbibe the Nomadic identity of the Kalbelias. Each tensile membrane shelters either the building block partially, or the open spaces or courtyards.

f) Steps forming the Amphitheatre: As for the Amphitheatre in the campus, the steps acquire a module conjuring the possibility of a convenient seating. The set of steps focuses towards the stage meant for music and dance performances. This amphitheatre would provide an ideal location for performances during festivals and celebrations.

g) Helical Stairs: The helical staircases applied in the curved arrangement of the staggered cubical enclosures, lead to the first-floor terrace. They transform the casual act of climbing upwards to the first floor, into a ceremonial event.

5. Materials and construction: 
The structure adopted in all the building blocks is RCC framed structure. The walls are merely an infill. The walls are cavity walls with an inner and an outer layer of bricks. The outer (exterior) layer of bricks is cladded with dressed stone blocks of Jaisalmer (Yellow sandstone) with a rustic texture finish. The tents are tensile with neoprene fabric as the skinning material, which is flexible and durable.

\section{Spatial Narratives in the envisioned experiential journey within the proposed campus}

When looked upon from a distance, the campus was envisaged to seem like a cluster of tents, reminiscent of the Dera - the traditional clusters of tents erected by the Kalbelias, whenever they would migrate to a village or a town. As one would come closer, he would encounter a welcoming entrance to the campus, inviting the visitor to explore further.

As the visitor enters, he would be greeted with a water-body with lotus-flowers offering a pinch of fragrance. Here, the visitor would take a pause to ponder over the vignette created by the structures and landscape in the campus. The visitor would then discover the pergolas sheltered with creepers; on taking a right turn with a slight tilt of $30^{\circ}-35^{\circ}$. This would enchant the visitor to mover further towards it. As the visitor would traverse through the creepers, he would be rewarded with a discovery of a node, which would resemble a traditional street chowk. This is when, the visitor would unfold a vista that not only would look like the heart of the campus but would offer him the privilege to choose the path further. This whole street-like vista would be orchestrated by the clusters of staggered cubical structures generating a play of concealment and revelation; which would charm the visitor to make a choice and navigate further. The penetration into any of the clusters acting as physical buffers, would be rewarded by the unfolding of another semi-open or an open courtyard guarded by the clustered cubical structures. Each such courtyard or even the amphitheatre, for that matter symbolizes the Indian notion of 'World within a world' - A microcosm within a cosmos. Each such courtyard is complete within itself with the built mass surrounding it, creating an introverted response; and yet is a part of the larger schema.

As the visitor moves further through the street, he would come across a node with a huge tree which would be looked upon by the terrace of the adjacent building. The occurrence of a tree in the middle of the movement path, would give the visitor a chance to pause and ponder over the spaces around and the assemblage of structures around. Here, the visitor would be able to peek to the spaces behind this structure, through the vertical fins and the voids between the cubical enclosures on the ground floor of the building. The visitor could either turn slightly right to the canteen or could navigate through the voids between the cubical enclosures on the ground floor of the adjacent building near the tree. If he chooses to navigate through these intriguing voids, he would be greeted with another water body with lotus flowers, which would guide further movement to the right, towards the last cluster of structures which forms the accommodation. This cluster would greet the visitor with a common courtyard under the tent, which is overlooked by all the units of the accommodation. Here, the visitor could choose to climb up to the residential units of the first floor of any of the 3 building blocks or could access the landscape around the back of the blocks, through the gaps between the blocks.

Thus, constantly changing axis and points of view, would keep on appealing the visitor through different visual perspectives. This phenomenon of kinesthetics is what makes architecture experiential. Therefore, movement through the space constitutes the experience than the externalities of the physical form or elements.

As the visitor completes his journey, he would have to follow the same path back to the entrance, to exit and end their journey. This is when he would bid farewell to the campus. But on 
the way back, he would recollect the remnants of the encounters rendered while exploring those spaces earlier. By then, the perceiver would have conditioned his mind, deepened his spirit and nourished his emotions with the everlasting impressions of the journey.

\section{The Proposed Design}

The design proposal for the undertaken project is depicted below through a sequential set of drawings:

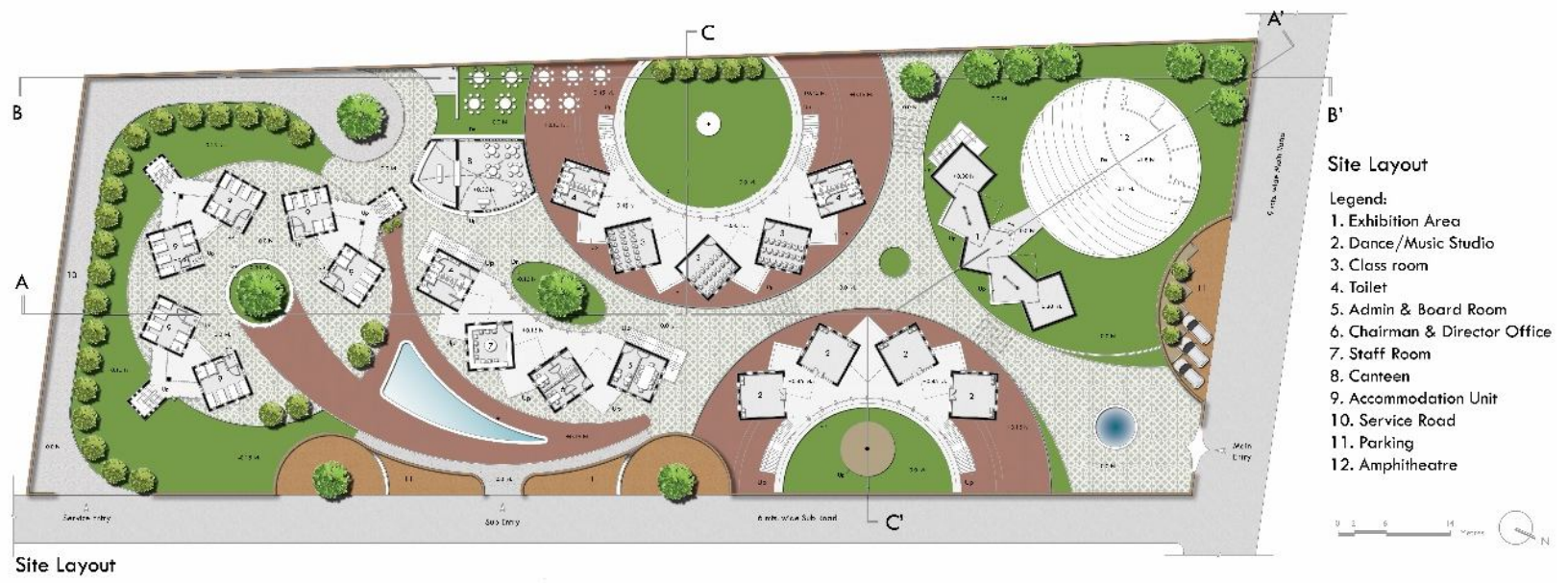

Figure 7: Site Layout

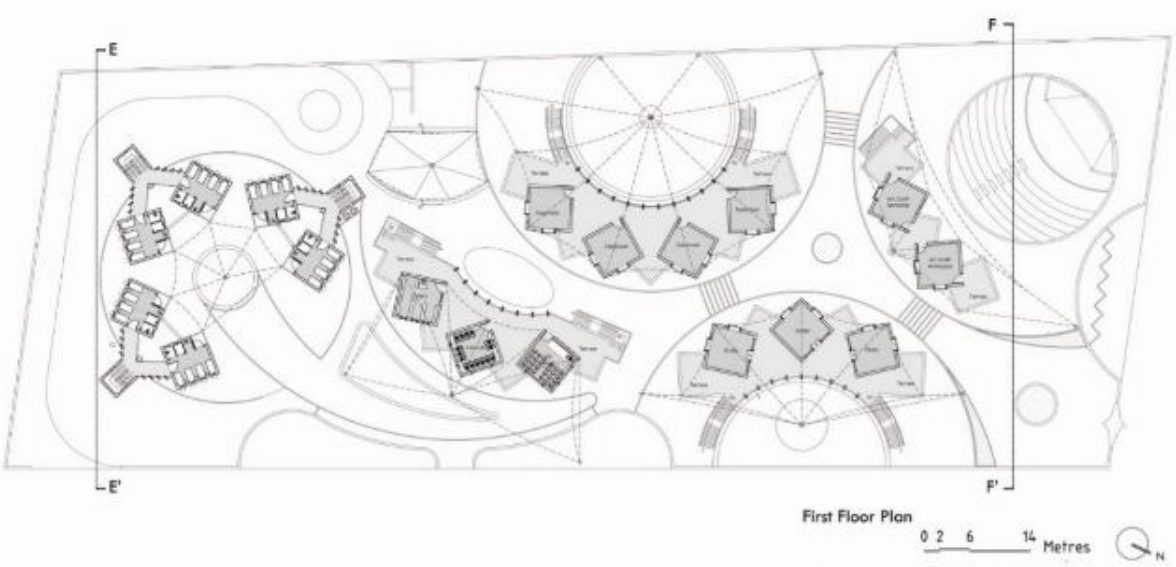

Figure 8: First Floor Plan

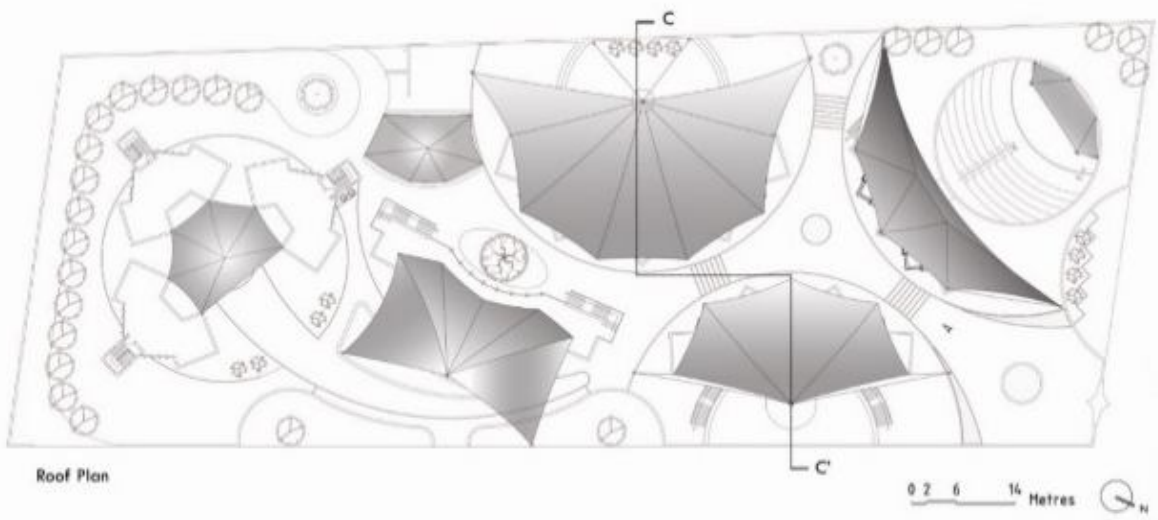

Figure 9: Roof Plan 
26 'Spatial Narratives' in Architecture: Designing a Dance Institute for the Nomadic Kalbelia community at Pushkar, Rajasthan, in India

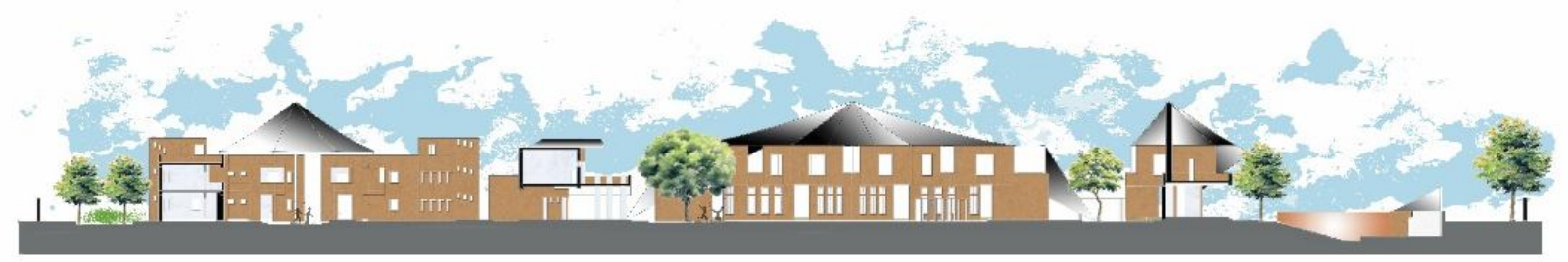

Section $A A^{\prime}$
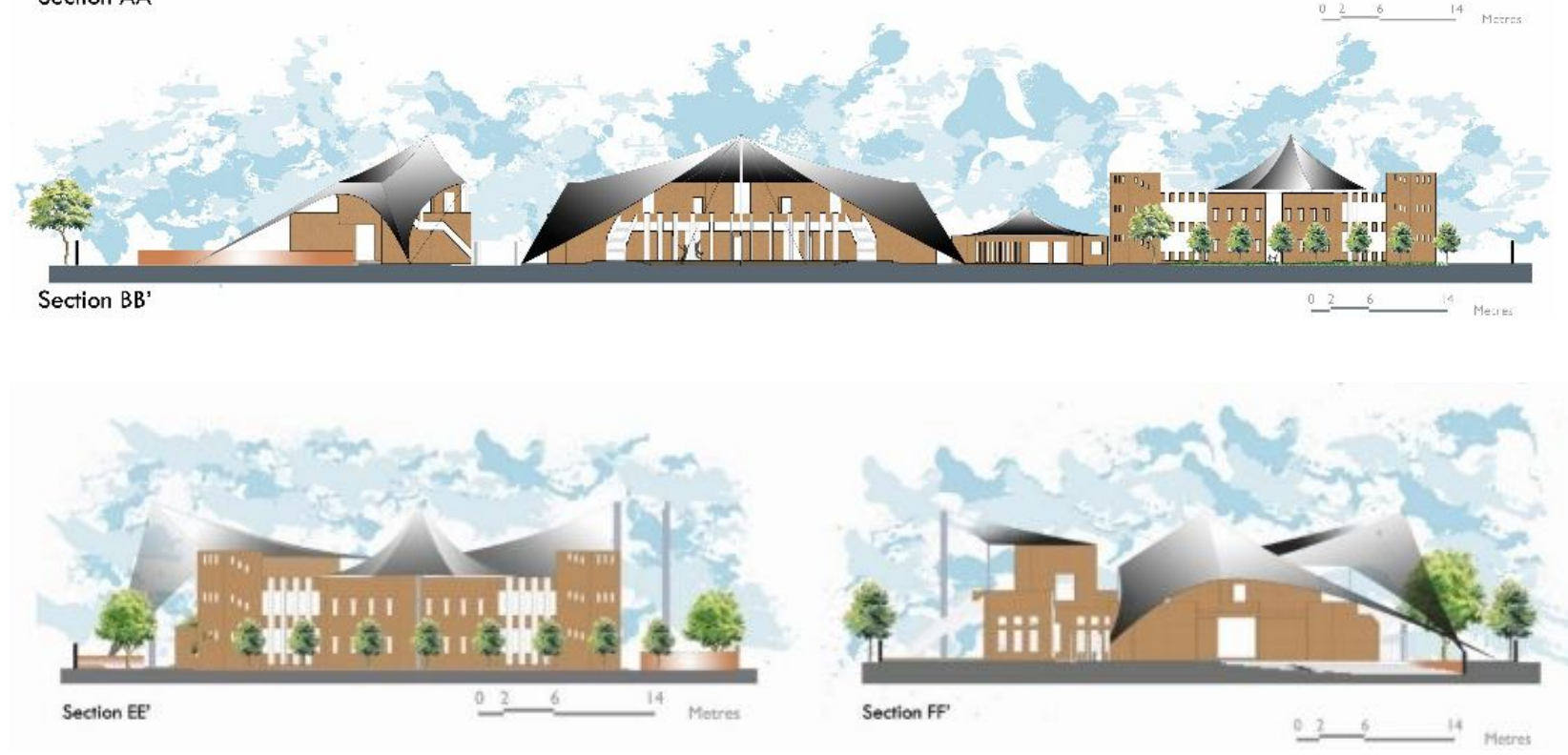

Figure 10: Sectional elevations
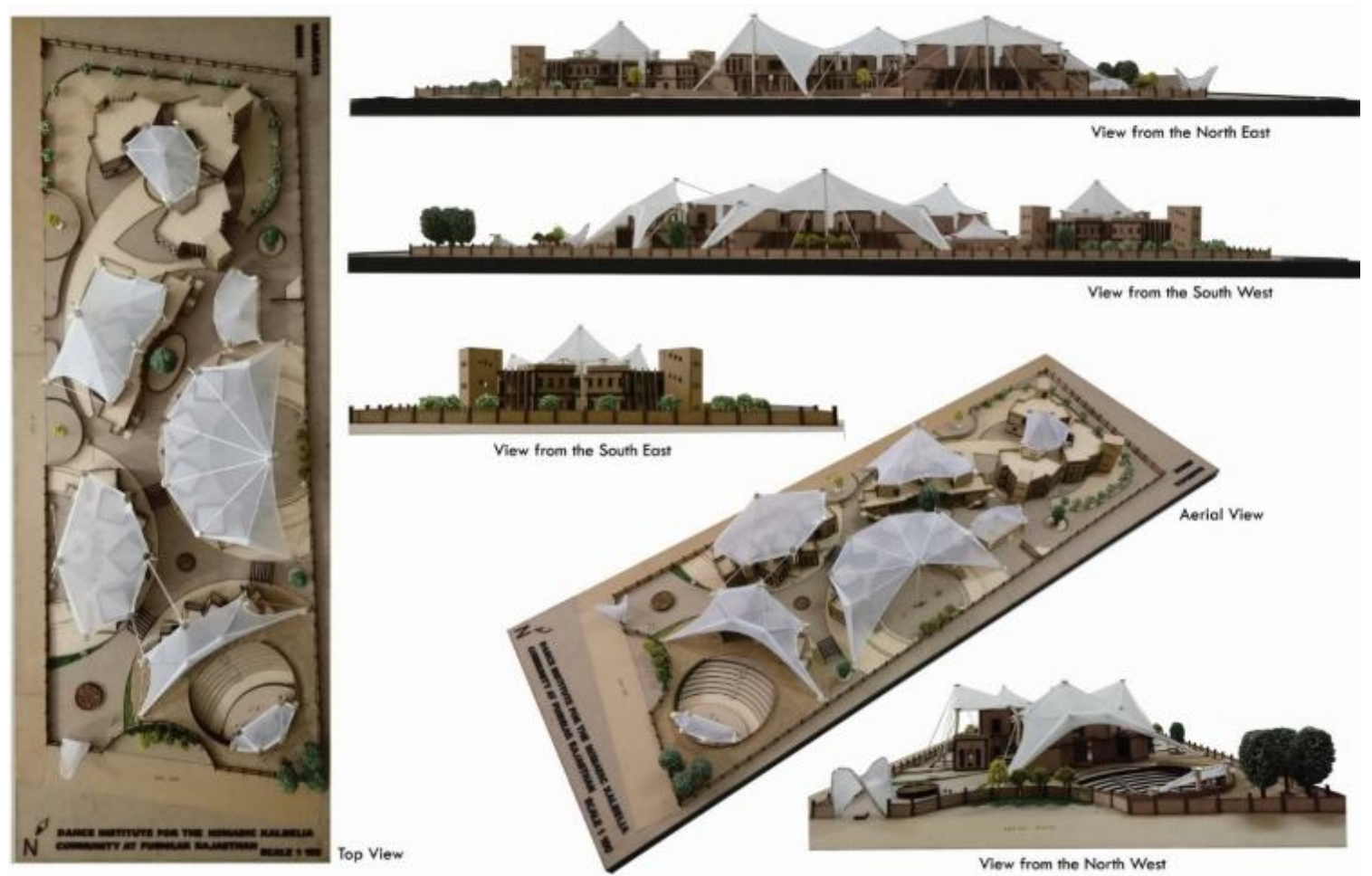

Figure 11: Photographs of the Model 


\section{Inferences}

The following inferences were derived after the design process carried out by the designer:

- Architecture embodies emotions. It is a chemistry between the 'conceptual' and the 'perceptual'. Architectural constructs set in motion a dialogue between the conceptual notions as conceived by the designer while conceiving the space and its perception as deciphered by the perceiver guided through the senses of his body as well as his mind. (Pandya, Concepts of Space in Traditional Indian Architecture, 2013).

- The 'Contextual wisdom' imbibed in our vernacular architecture, must be extracted and re-interpreted while designing contemporary projects. However, the architectural language developed could be altogether different in each project with respect to today's lifestyle, its complexity, budget, choice of materials, taste of the designer and the client's personal inclinations. For the same, a designer must take a dip in history of the context, understand its socio-cultural, economic and political dynamics; and replenish the poverty of his imagination.

- Each project must speak of its 'Identity' which expresses its time, space and people. However, this does not mean that each building must shout out for acquiring attention. At times, the identity could also be subtly expressed without disrupting the overall harmony.

- Never resort to 'Space-labelling'. Always go for 'Space-making'.

- An Architect is not merely a technical problem solver. He's more than that. He becomes the narrator, because the buildings designed by him are expressions, gestures and stories communicated to the world.

- Traditional Indian Architecture is essentially experiential. It gives clues as to how various elements, spaces and surfaces be organized and embellished to amuse the visitor, evoke emotions, convey ideas, encode messages, create mystery, invite exploration and feel celebrated. All these tricks could help us, the contemporary designers, to accomplish designs which are grounded in the local context, flaunt our ethos and yet yearn for timelessness.

\section{Acknowledgements}

Sincere thanks to Architect Yatin Pandya for his valuable guidance and feedback during the inception of the thesis project which was a great help to form the sequential list of design decisions and to pen down the spatial narratives of the design.

Hearty gratitude to Prof. Bhagyajit Raval, for his inputs while furnishing the design proposal of the undertaken project.

\section{Notes}

This paper is a refined extract from the dissertation of Ms. Namrata Singh, submitted in the partial fulfilment for the award of the degree of Bachelor of Architecture; in the year 2017 to Parul Institute of Architecture and Research. 


\section{References}

Alzahrani, D. A. (2013, January). The Adoption of a Standard Definition of Cultural Heritage. International Journal of Social Science and Humanity, 3, 9-12. doi:10.7763/IJSSH.2013.V3.182

Pandya, Y. (2013). Concepts of Space in Traditional Indian Architecture (2nd ed.). (C. Kagal, Ed.) Ahmedabad, Gujarat, India: Mapin Publishing Pvt. Ltd. Retrieved 2017

Pandya, Y. (2014). Elements of Spacemaking (2nd ed.). (N. M. Editorial, Ed.) Ahmedabad, Gujarat, India: Mapin Publishing Pvt. Ltd. Retrieved 2017

Pandya, Y. (2014, March 7). Workshop on 'Space-making in Architecture'. (M. Hajarnis, Interviewer) Vadodara, Gujarat, India.

UNESCO. (2012). Representative List of the Intangible Cultural Heritage of Humanity 2010 - 2011. Sector for Culture. Paris: UNESCO. Retrieved January 1, 2017, from WWW.UNESCO.ORG/CULTURE/ICH

Ms. Namrata Singh is an Architect graduated from Parul Institute of Architecture and Research, Gujarat Technological University, Chandkheda, Ahmedabad, Gujarat, India.

Prof. Maulik Hajarnis is a core faculty member of the Parul Institute of Architecture and Research, Faculty of Architecture, Parul University, Waghodia, Vadodara, Gujarat, India. (orcid.org/oooo0002-9502-4173) 